\title{
Characteristics of industrial structure evolution and isomorphism in Central Asia
}

\author{
KANG Lei ${ }^{1}$, LIU Yi ${ }^{1,2}$
}

1. Key Laboratory of Regional Sustainable Development Modeling, Institute of Geographic Sciences and Natural Resources Research, CAS, Beijing 100101, China;

2. College of Resources and Environment, University of Chinese Academy of Sciences, Beijing 100049, China

\begin{abstract}
This study undertakes a systematic examination of characteristics of the spatio-temporal evolution of industrial economies in Central Asia from the perspectives of industrial scale, structural rationality, industrial competitiveness, and industrial isomorphism. The results show that industrial structures in Central Asian countries are becoming increasingly advanced, with certain differences among them in the characteristics of this evolution. Kazakhstan has long had a tertiary-secondary-primary industrial pattern, and productive services have played an increasingly prominent role in the development of its tertiary industry. The transformation of the industrial structure in Uzbekistan, from a secondary-tertiary- primary pattern at its independence from the Soviet Union to a tertiary-secondary-primary pattern, is apparent. Tajikistan's industrial structure has also changed significantly in recent times. Its secondary industries shrunk while tertiary industries developed rapidly. In Kyrgyzstan, the ratios of secondary and tertiary industries to total industrial output have fluctuated significantly while considerable progress has been made in the service sector. The industrial structure of Turkmenistan is significantly lower than the other countries, and Turkmenistan is the only country in the Central Asian region which still shows a tertiary-secondary-primary industrial pattern. The feasibility and competitiveness of the industrial structures of these five Central Asian countries have different characteristics. Kazakhstan has structural advantages but lags in competitiveness, Uzbekistan is driven by both structural and competitive advantages, Tajikistan enjoys structural advantages while Kyrgyzstan lags behind in competitiveness, and Turkmenistan has a competitiveness-driven economy. Furthermore, values of the similar coefficient index of the three industrial structures in these countries were mostly above 0.95 , the coefficients of the secondary industrial subdivisions in some countries were below 0.85 , and those of tertiary industrial subdivisions among most countries were above 0.89 , indicating considerable similarities in industrial structure among them. These findings are important in the context of establishing an effective industrial development strategy for the Silk Road Economic Belt, improving international cooperation, and upgrading industrial structures to achieve economic prosperity.
\end{abstract}

Keywords: industrial structure; evolution; industrial isomorphism; shift-share analysis; similar coefficient index; Central Asian countries

Received: 2020-03-17 Accepted: 2020-07-31

Foundation: The Strategic Priority Research Program of the CAS, No.XDA20040400; National Natural Science Foundation of China, No.41801114

Author: Kang Lei (1989-), PhD and Assistant Professor, specializing in economic geography and regional development. E-mail: kanglei@igsnrr.ac.cn 


\section{Introduction}

The countries of Central Asia became independent following the fall of the Soviet Union in 1991. As the region has since gradually transformed from a planned economy to a market-driven economy, it has opened up to the world, and the rapid development of its energy industry has led to Central Asia becoming an emerging force in the global economy (Tang and Chen, 2015). Current research on the Central Asian economy has tended to focus on an analysis of characteristics of the overall development and trends of the economy. Due to globalization and international relations, the economy of Central Asia has undergone various stages of development in the past 20 years. Rapid economic growth has been observed in general, but with significant differences among the five countries forming the region (Kazakhstan, Uzbekistan, Turkmenistan, Kyrgyzstan, and Tajikistan) (Tang and Chen, 2015; Hu, 2004). Most research has focused on regional economic cooperation, and has considered such aspects of it as complementarities, the importance of cooperation, potential and prospects for cooperation, modes of cooperation, strategies for cooperation between countries of the region and those outside it, and outstanding problems related to the economy, trade, and energy (Wang, 2002; Bi and Shi, 2010; Yang et al., 2015; Li et al., 2019). As important elements of economic growth, industrial development and structural evolution are closely related to national and regional economic development. In this regard, the development of industry in Central Asia is currently a popular subject of research in academic circles. After the break-up of the Soviet Union, Central Asia first experienced a period of turbulent depression and stagnation, followed by a period of progress accompanied by significant spatial and temporal changes in the industrial structure. It will help the reader to gain a better and more complete understanding of the economic development of Central Asia if a detailed analysis of the evolution of its industrial structure is undertaken because this can help clarify the effect of industrial development on economic growth in the five countries. This approach can also help lay the foundation for international collaborative research on economic development in the region. From another perspective, Central Asia is located in the heart of the Eurasian continent, and is regarded as a key area covered by the Belt and Road Initiative (Megoran and Sharapova, 2005; Paulo, 2014) as well as a region where China should promote cooperation for the construction of the Silk Road Economic Belt. The strengthening of cooperation in production capacity between China and Central Asian countries is a priority for the future. It is thus important to analyze in detail characteristics of the evolution of the industrial structure in the region and document the industrial attributes of Central Asian countries. In this context, it is desirable to build an effective strategy for industrial development for the Silk Road Economic Belt, realize close international partnerships, and promote the upgrade of industrial structures to achieve economic prosperity. For instance, a study has analyzed the industrial structure of the five Central Asian countries in terms of the basic industrial sectors: that is, the primary, secondary, and tertiary industries. The analysis revealed that all five countries had entered the industrialization era based on comparisons of their industrial structures with their employment structures, and a trend of continual development from the primary stage of production to an advanced industrialization stage was noted (Wen, 2011). Some manufacturing industries have been selected for statistical analysis to determine the spatial pattern and structural characteristics of their development. It has been noted that the manufacturing structure of the five countries is relatively simple, with an uneven spatial distribution and a heavy industrial structure, which means the industrial structure is 
dominated by heavy industries that produce production materials (Shi et al., 2013). As an important sector for production and a major driver of economic development in Central Asia, developments in the energy industry have been analyzed from the perspectives of energy production, product consumption, and trade. The results confirmed that economic development in Central Asia is heavily dependent on the energy industry. The rich energy resources of Kazakhstan, Uzbekistan, and Turkmenistan have become the main growth points of their economic development (Tang et al., 2014).

A summary of research on the economic development and evolution of the industrial structure in Central Asia has shown that qualitative and anecdotal research based on historical and statistical data is prominent in the literature. Research on the evolution of the industrial structure in Central Asian countries has focused mainly on the temporal evolution of the industrial output and its proportion of the GDP, and reflects the evolution from the perspective of "scale," which often leads to too broad a set of conclusions that also lack any element of quantification. Few studies have examined problems in the evolution of the industrial structure, and its rationality and competitiveness. Prevalent research has mostly taken a single country as study area, and the lack of comparative research between countries is not conducive to gaining a comprehensive understanding of the overall situation of industrial development in Central Asia and intra-regional differences. It is clear that quantitative and scientific discussion on the characteristics of the industrial structure and its spatio-temporal evolution in Central Asia is lacking, and the available research is not systematic. In addition, the research shows that although Central Asian countries have taken measures to reshape the industrial structure and stimulate economic development since their independence, the pattern of a unitary industrial structure has not fundamentally changed (Gao, 2013), and has inevitably led to the problem of industrial isomorphism. This is related to the endowment of natural resources in the region and industrial policies of the countries (Chang, 2001). Most Central Asian countries are still in the early stages of economic development, and industrial isomorphism will affect their regional advantages and competitiveness (Liu et al., 2016). However, no research to date has measured and identified the industrial isomorphism in Central Asia.

This study focuses on the five Central Asian countries as study area. The evolutionary trends and characteristics of their primary, secondary, and tertiary industries as well as key sectors within each are first analyzed. All of the Central Asian region is then used as a reference system, the shift-share method is applied to quantify the rationality and competitiveness of the industrial structure of each country, and dynamic characteristics of the evolution of the industrial structure of each are evaluated. The study also calculates the coefficients of structural similarity at different industrial levels to characterize the isomorphic characteristics and extent of industrial development among Central Asian countries. The aim is to provide a basis for further discussion and interpretation of the relationship between the industrial structure and economic integration in Central Asia.

\section{Materials and methods}

\subsection{Study area}

Central Asia is located in the hinterland of Eurasia, lying between $50^{\circ}-80^{\circ} \mathrm{E}$ and $35^{\circ}-55^{\circ} \mathrm{N}$, and comprises Kazakhstan, Uzbekistan, Tajikistan, Kyrgyzstan, and Turkmenistan (Figure 1). 


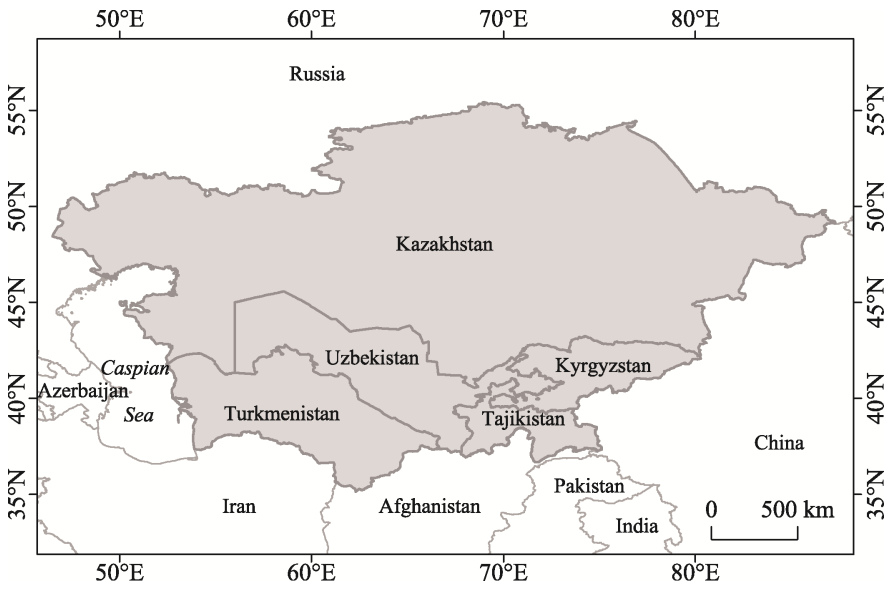

Figure 1 Location of Central Asian countries
These five countries, bordering Russia in the north, Iran and Afghanistan in the south, China in the east, and the Caspian Sea in the west, occupy an area of nearly 4 million $\mathrm{km}^{2}$ (Wang et al., 2015). The five Central Asian states gained independence from the Soviet Union in late 1991. They all experienced severe economic recession at the beginning due to the transition from a planned economy to a market-driven system. By 1999, the countries had emerged from the transitional economic chaos and begun recording economic growth (Sun et al., 2017). In 2016, the GDP of the five countries was 306.136 billion US dollars (USD), accounting for $0.41 \%$ of the world economy. The ratios of the three industrial sectors (primary: secondary: tertiary) were 9.14: $36.60: 54.26$, and the per capita GDP reached 4370 USD.

\subsection{Data sources}

According to the industry classification of the United Nations Statistics Division, primary industries include agriculture, hunting, forestry, and fishing, secondary industries include mining, manufacturing, utilities, and construction, and tertiary industries include the wholesale and retail trades, restaurants and hotels, transport, storage, communication, and other activities. Based on this classification, this study used GDP output data of the three industrial sectors and key subdivisions of the five Central Asian countries from 1990 to 2016. The industrial output data used were mainly from the United Nations Statistics Division (http://data.un.org/Data.aspx?q=+industries\&d=SNA\&f=group_code\%3a205), supplemented by statistical data from the Central Asian countries, and were calculated at constant prices based on data for 2010. Currency units were converted into USD to facilitate comparisons between countries.

\subsection{Methods}

\subsubsection{Shift-share method}

The shift-share method is an effective method to analyze structural problems in the economy (Kundsen, 2000). The basic premise is that a change in the regional economy is seen as a dynamic process, with the larger regional economic development serving as a frame of reference. Then, changes in regional economic development over a certain period can be broken down into a share component, a structural deviation component, and a competitiveness deviation component to identify industrial sectors with competitive advantages in the region (Lu et al., 2008). The model can be described as follows (Liu and Shen, 2007; Lu et al., 2008):

Suppose that after a period $[0, t]$, the gross economic outputs for a region and the larger region have changed. Set the scale of the regional gross output for the initial period or the 
base year to $b_{0}$ and that of the final period to $b_{t}$. According to specific rules, the regional economy is divided into $n$ industrial sectors, with $b_{j, 0}$ and $b_{j, t}(j=1,2, \ldots, n)$ representing the scales of the industrial sector $j$ in the initial and final stages of the region, $B_{0}$ and $B_{t}$ representing the gross economic outputs of the larger region in the initial and final stages, and $B_{j, 0}$ and $\mathrm{B}_{j, t}$ representing the scales of the industrial sector $j$ of the larger region in the initial and final stages, respectively. Then, the rates of change of any industrial sector $j$ of the region and the larger region during this period are $r_{j}$ and $R_{j}$, respectively.

$$
r_{j}=\frac{b_{j, t}-b_{j, 0}}{b_{j, 0}}, R_{j}=\frac{B_{j, t}-B_{j, 0}}{B_{j, 0}}(j=1,2,3, \cdots, n)
$$

Then, standardize the outputs for all industrial sectors of the region according to their share of the industrial sectors of the larger region as follows:

$$
b_{j}^{\prime}=\frac{b_{j, 0} \times B_{j, 0}}{B_{0}}(j=1,2,3, \cdots, n)
$$

In this way, the amount of growth $G_{j}$ of the industrial sector $j$ in each region during the period $[0, \mathrm{t}]$ can be subdivided into the share component $N_{j}$, the structural deviation component $P_{j}$, and the regional competitiveness deviation component $D_{j}$.

$$
\begin{gathered}
G_{j}=N_{j}+P_{j}+D_{j} \\
N_{j}=b_{j}^{\prime} \times R_{j} \\
P_{j}=\left(b_{j, 0}-b_{j}^{\prime}\right) \times R_{j} \\
D_{j}=b_{j, 0} \times\left(r_{j}-R_{j}\right)
\end{gathered}
$$

In this study, the regional share component is the redistribution of the GDP of each country based on the industrial structure and growth rate of all of Central Asia. The structural deviation component is a comparison of the three industrial sectors for each country and those for Central Asia. The competitiveness deviation component is a measure of the industrial growth rate of each country and that of Central Asia.

The total growth of the region can be expressed as follows:

$$
G=N+P+D=\sum_{j=1}^{n} b_{j}^{\prime} \times R_{j}+\sum_{j=1}^{n}\left(b_{j, 0}-b_{j}^{\prime}\right) \times R_{j}+\sum_{j=1}^{n} b_{j, 0} \times\left(r_{j}-R_{j}\right)
$$

$K_{j, 0}=b_{j, 0} / B_{j, 0}$ and $K_{j, t}=b_{j, t} / B_{j, t}$ represent the ratios of growth of industrial sector $j$ of the region to that of the larger region in the initial and final periods, respectively. The growth rate of the region relative to the larger region $L$ can be expressed as follows:

$$
\begin{aligned}
L & =\frac{\sum_{j=1}^{n} b_{j, t}}{\sum_{j=1}^{n} b_{j, 0}} / \frac{\sum_{j=1}^{n} B_{j, t}}{\sum_{j=1}^{n} B_{j, 0}}=\frac{\sum_{j=1}^{n} K_{j, t} \times B_{j, t}}{\sum_{j=1}^{n} K_{j, 0} \times B_{j, 0}} / \frac{\sum_{j=1}^{n} B_{j, t}}{\sum_{j=1}^{n} B_{j, 0}} \\
& =\left[\frac{\sum_{j=1}^{n} K_{j, 0} \times B_{j, t}}{\sum_{j=1}^{n} K_{j, 0} \times B_{j, 0}} / \frac{\sum_{j=1}^{n} B_{j, t}}{\sum_{j=1}^{n} B_{j, 0}}\right] \times\left[\frac{\sum_{j=1}^{n} K_{j, t} \times B_{j, t}}{\sum_{j=1}^{n} K_{j, 0} \times B_{j, t}}\right]=W \times u
\end{aligned}
$$


In the above, $W$ and $u$ represent the effects of the structural index and the regional competitive index, respectively. If $L$ is greater than one, the given region is growing more quickly than the entire region. If the value of the structural deviation component is large, $W$ is greater than one, indicating that the ratio of fast-growing industrial sectors in the regional economy is significant, the overall economic structure of the region is positive, and the industrial sector contributes significantly to economic growth. However, the industrial structure needs to be adjusted if the value of the competitiveness deviation component is large, with $u$ greater than one, indicating that all industrial sectors have strong growth momentum and strong competitiveness. In contrast, if $u$ is less than one, this indicates that the industrial sectors have a low competitiveness and a declining position in the economy.

\subsubsection{Similarity coefficient index of industrial structure}

Industrial isomorphism has long been a popular subject of research in academic circles. It refers to the phenomenon whereby the evolution of the types of industrial composition, quantity ratios, spatial distributions, and methods of correlation among regions in the process of economic development tends to be consistent, and the structural differences gradually narrow (Zhu et al., 2007). In this paper we calculate the similarity coefficient index introduced by UNIDO, the abbreviation of United Nations Industrial Development Organization, in the 1980s at three levels - industrial structure, and the internal structures of the secondary and tertiary industries - for different regions. The purpose is to measure the degrees of similarity and difference in the composition of industrial sectors between regions. The similarity coefficient index is expressed as follows (UNIDO, 1979):

$$
S_{i j}=\sum_{k=1}^{n} x_{i k} x_{j k} / \sqrt{\sum_{k=1}^{n} x_{i k}^{2} \sum_{k=1}^{n} x_{j k}^{2}}
$$

where $S_{i j}$ is the similarity coefficient of regions $i$ and $j, x_{i k}$ is the ratio of the output of industry $k$ to the entire industrial output of area $i$, and $x_{j k}$ is the ratio of the output of industry $k$ to the entire industrial output of area $j$.

$S i j$ varies between zero and one. When $S_{i j}=0$, it means that regions $i$ and $j$ have completely different industrial structures. When $S_{i j}=1$, it means that regions $i$ and $j$ have the same industrial structure. The closer to one the value of $S_{i j}$ is, the greater the degree of industrial isomorphism between the compared regions is. Otherwise, the degree of isomorphism is low. According to empirical judgment, when evaluating the similarity between countries, 0.85 is used as the standard (Wang et al., 2008).

\section{Results}

\subsection{Evolutionary trends of industrial development in Central Asian countries}

3.1.1 Industrial structure of Central Asian countries is becoming more advanced, with an increasingly prominent tertiary-secondary-primary industrial pattern

From the perspective of outputs and their relative portions in the three industrial sectors in Central Asia (Figure 2), a decline was noted in the national economies of the five countries on gaining independence from the Soviet Union. In particular from 1990 to 1995, the outputs of the secondary and tertiary sectors decreased from 540.17 and 72.768 billion USD to 351.51 and 40.438 billion USD, respectively, representing declines of $35 \%$ and $44.4 \%$. The relative proportions of the three industries changed from 13.03: $37.06: 49.94$ to $15.32: 39.44$ : 
45.25 , respectively. After 1995, the outputs of the three sectors started to recover. The proportion of the primary sector continued to decline slowly, that of the secondary sector remained at about $40 \%$ for many years, and began to decline after 2010 , and the proportion of the tertiary sector generally showed a steady rise, exceeding $50 \%$ in 2006 for the first time and reaching $54.26 \%$ in 2016. The three industrial sectors in Central Asia made significant progress on the whole. The tertiary industry in Kazakhstan, Uzbekistan, and Tajikistan developed rapidly, and has even become the main driving force of the economy, much like the traditional secondary industry. Kyrgyzstan has also exhibited a tertiary-secondary-primary industrial pattern over the years, but the relative proportions of the secondary and tertiary industrial sectors clearly fluctuated before 2008. The trend of upgrades to the industrial structure in Kyrgyzstan was not as significant as those in the former three countries, and was closely related to the large economic fluctuations caused by political instability and the 2008 global financial crisis. The level of advancement in Turkmenistan's industrial sector was the poorest in Central Asia, with a secondary-tertiary-primary industrial pattern.
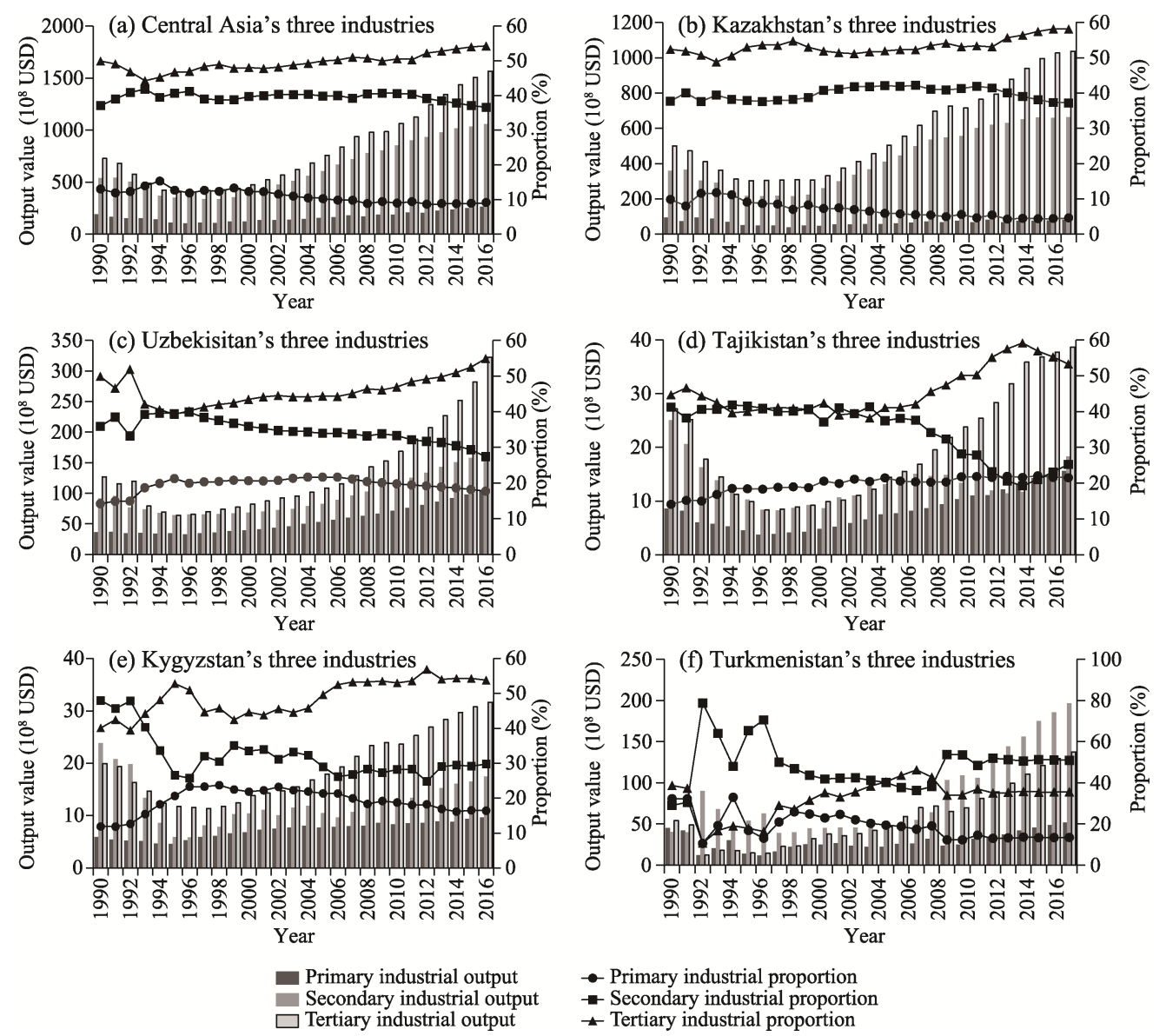

Figure 2 Structural trends of evolution of the three industrial sectors in Central Asia from 1990 to 2016

3.1.2 Evolutions of the industrial structures of Central Asian countries show different characteristics from the perspective of subdivided industries

To better understand the characteristics of the three industries, this paper analyzes the evolu- 
tion of major industrial subdivisions in Central Asian countries from 1990 to 2016 based on the outputs of their sub-sectors. The proportions of outputs of the subdivided industries in the five Central Asian countries in different years are shown in Table 1.

Table 1 The proportions of outputs of subdivided industries from 1990 to 2016 (\%)

\begin{tabular}{|c|c|c|c|c|c|c|c|}
\hline Country & Year & $\begin{array}{l}\text { Agriculture, } \\
\text { hunting, for- } \\
\text { estry, fishing }\end{array}$ & $\begin{array}{l}\text { Mining, man- } \\
\text { ufacturing, } \\
\text { utilities } \\
\end{array}$ & Manufacturing & Construction & $\begin{array}{c}\text { Wholesale, retail } \\
\text { trade, restaurants } \\
\text { and hotels }\end{array}$ & $\begin{array}{l}\text { Transport, } \\
\text { storage, com- } \\
\text { munication }\end{array}$ \\
\hline \multirow{4}{*}{ Kazakhstan } & 1990 & 9.80 & 26.91 & 10.34 & 10.42 & 11.23 & 13.61 \\
\hline & 2000 & 6.97 & 35.13 & 12.95 & 3.89 & 12.89 & 10.22 \\
\hline & 2010 & 4.51 & 32.90 & 11.32 & 7.70 & 13.86 & 11.12 \\
\hline & 2016 & 4.35 & 27.25 & 10.24 & 7.59 & 16.45 & 13.07 \\
\hline \multirow{4}{*}{ Uzbekistan } & 1990 & 17.60 & 37.58 & 31.58 & 6.92 & 7.39 & 18.43 \\
\hline & 2000 & 19.36 & 28.74 & 24.11 & 4.95 & 8.04 & 9.09 \\
\hline & 2010 & 17.95 & 24.23 & 20.28 & 6.03 & 9.59 & 11.76 \\
\hline & 2016 & 16.85 & 20.81 & 17.41 & 5.23 & 17.07 & 13.59 \\
\hline \multirow{4}{*}{ Tajikistan } & 1990 & 12.54 & 27.81 & 27.81 & 8.89 & 15.07 & 4.56 \\
\hline & 2000 & 18.46 & 27.13 & 27.13 & 6.14 & 14.88 & 3.80 \\
\hline & 2010 & 19.59 & 14.74 & 14.74 & 10.23 & 20.24 & 11.16 \\
\hline & 2016 & 19.35 & 12.71 & 12.71 & 9.95 & 25.41 & 9.12 \\
\hline \multirow{4}{*}{ Kyrgyzstan } & 1990 & 12.26 & 40.18 & 34.83 & 9.39 & 11.37 & 7.89 \\
\hline & 2000 & 21.15 & 28.70 & 23.18 & 3.72 & 10.88 & 4.28 \\
\hline & 2010 & 17.45 & 20.74 & 16.86 & 5.52 & 17.17 & 9.07 \\
\hline & 2016 & 15.33 & 17.82 & 13.70 & 9.98 & 21.66 & 9.44 \\
\hline \multirow{4}{*}{ Turkmenistan } & 1990 & 32.89 & 25.90 & 25.53 & 3.71 & 8.91 & 12.12 \\
\hline & 2000 & 22.95 & 35.04 & 33.01 & 6.77 & 3.51 & 6.63 \\
\hline & 2010 & 14.07 & 38.99 & 36.75 & 7.84 & 4.21 & 6.43 \\
\hline & 2016 & 13.11 & 41.38 & 39.00 & 8.32 & 4.08 & 6.24 \\
\hline
\end{tabular}

(1) Kazakhstan's service industry has developed rapidly while manufacturing still plays an important role in the national economic system

Although the agricultural output of Kazakhstan, close to 10 billion USD, was relatively high, its proportion of GDP was the lowest among Central Asian countries, decreasing from $9.8 \%$ in 1990 to $4.35 \%$ of the total in 2016. Its outputs of mining and manufacturing, however, increased, reaching 51.9 billion USD in 2016. The mining sector accounts for more than $15 \%$ of the GDP and the manufacturing industry nearly $20 \%$. Kazakhstan's industry thus makes a significant contribution to the economy. The country is still dominated by the oil and gas industry, metal and non-metal mining industry, and the smelting industry, all of which are influenced by international market conditions. Coking and metallurgical production have developed well. In recent years, the scale of automobile manufacturing has also grown rapidly. The output of the entire manufacturing industry in Kazakhstan increased from 9.962 billion USD to 19.5 billion USD from 1990 to 2016. As the engine of Kazakhstan's industrialization, the manufacturing industry occupies the core position among the five Central Asian countries. The output of the traditional service industry continues to grow as well. The output of the wholesale and retail sector was 31.329 billion USD in 2016, and 
that of the transport, storage, and communication sector was 24.886 billion USD, more than twice as much as those in 2000 . The ratio of the outputs of the two sectors to the overall economy is now $40 \%$.

(2) Uzbekistan's industrial structure is diversified and advanced, with potential for industrial development

Uzbekistan's agricultural output has grown steadily over the years, from 3.607 billion USD in 2000 to 10.402 billion USD in 2016, accounting for more than $16 \%$ of the total economy. The output of livestock products, grains, potatoes, and fruits has been increasing in recent years, laying a solid foundation for the development of the national economy and an improvement in the residents' standards of living. Meanwhile, the tertiary industry has shown vigorous growth. In particular, the output of the wholesale and retail trade has increased from 1.515 billion USD to 10.541 billion USD in the last six years. Correspondingly, its proportion has also increased significantly from less than $8 \%$ to $17.07 \%$, emerging as the leading force in the tertiary industry. The output of the transport, storage, and communication sector resumed its growth to 8.393 billion USD in 2016 , accounting for $13.07 \%$ of the economy, after a period of decline. By comparison, the share of Uzbekistan's secondary industry has shown a downward trend, but its output has continued to grow steadily from 7.702 billion to 12.846 billion USD. The output of the manufacturing industry, including the oil and gas industry, non-ferrous metal smelting, and heavy machinery manufacturing, reached 10.751 billion USD in 2016 as Uzbekistan's secondary industrial system is relatively complete. The mining of natural gas, oil, and gold form its pillars, and heavy machinery manufacturing is also relatively developed. However, a lack of high-end manufacturing capacity has affected the secondary industry's role in stimulating the economy to a greater extent.

(3) Tajikistan has a relatively simple industrial structure, the manufacturing industry is lagging, but the wholesale and retail trade industry has developed

Tajikistan's agriculture industry has achieved stable growth, and its output increased from 0.857 billion USD in 1990 to 1.561 billion USD in 2016. Whereas the agricultural development of other countries in the region has undergone uncertain changes, Tajikistan's agricultural output as a proportion of the economy has increased steadily from $12.54 \%$ to $19.35 \%$. After independence, the industrial links between Tajikistan and other former Soviet republics were severed, which had a significant impact on the local industry, and the proportion of output of the secondary industrial declined year by year. Tajikistan's industrial sectors include the mining of aluminum and hydropower generation. It is the largest primary producer of aluminum in Central Asia. Due to the impact of rising domestic industrial costs and falling international aluminum prices, a decline in aluminum production has directly led to a drop in its proportion of the secondary industrial output from $27.13 \%$ of 2000 to $12.71 \%$ of 2016. The share of construction has risen steadily since 2000 , and is mainly related to local infrastructure construction. The growth of the tertiary industry is more prominent, especially the wholesale and retail trade sector, with its output and proportion of the economy increasing from 1.029 billion USD, $15.07 \%$, to 2.05 billion USD, 25.41\%, from 1990 to 2016. As its import and export trade has played an increasingly significant role in driving economic growth, the wholesale and retail trade industry has developed.

(4) Kyrgyzstan's industrial development situation is grim, internal sectors have develop 
unevenly, but the service industry has grown steadily

Kyrgyzstan is a country reliant on traditional farming and animal husbandry. Its agricultural output has grown from 0.59 billion USD in 1990 to 0.965 billion USD in 2016, but the industry's proportion of the GDP has shown a downward tendency. In recent years, Kyrgyzstan has developed the construction industry, the output and proportion of the economy of which have grown to nearly 10\%. Manufacturing in Kyrgyzstan accounts for more than $50 \%$ of total industrial output, with the power industry and machinery manufacturing being important sectors. Large fluctuations in the output of gold mines have severely constrained industrial growth. Affected by the reduced mining of gold in the Kumtor Mine as well as reductions in power and oil production, mining as a pillar of Kyrgyzstan's economy has weakened. The country's total industrial output fell from 1.934 billion USD in 2000 to 1.122 billion USD in 2016, and its proportion of the GDP dropped significantly from $40.18 \%$ to $17.82 \%$. Overall, industrial development is facing severe shrinkage. The growth of the service industry is stable but other sectors are unevenly developed. The wholesale and retail trade industry has grown rapidly, accounting for $21.66 \%$ of the GDP in 2016, significantly higher than that of the transport, storage, and communication sector.

(5) Turkmenistan's agriculture and service industries are lagging behind, the oil and gas industry accounts for a large proportion of the economy, but the industrial structure is not advanced and diversified enough

Turkmenistan's agricultural output is low, and its proportion of the GDP dropped from $32.89 \%$ in 1990 to $13.11 \%$ in 2016 . The total industrial output, including mining and manufacturing, has grown rapidly, an increase from 3.542 billion USD to 16.37 billion USD, and its proportion of the GDP has also increased significantly from $25.9 \%$ to $41.38 \%$. Natural gas, and oil extraction and processing are the pillars of the economy. The power and textile industries have also developed rapidly, but that of the construction industry has been slow, with a low output. The output of the service industry is also low, and its proportion of the economy has been declining in recent years. The service industry is also underdeveloped.

\subsection{Dynamic evolution of industrial structure based on shift-share analysis}

Based on previous studies (Tang and Chen, 2015), and given the economic development of Central Asia, we argue that in a period of economic turbulence, Central Asian countries first experienced stagnation after independence and then recovery from 1990 to 1999. This was followed by a period of deepening market-oriented reform during 2000-2009, and finally stable development after 2010. Therefore, periods from 1990 to 1999, 2000 to 2009, and 2010 to 2016 were selected to analyze the evolution of the industrial structure of the five countries using the shift-share method. This section analyzes characteristics of the evolution of the industrial structure of each country and, by taking all of Central Asia as a reference system, assesses the rationality and competitiveness of their industrial structures.

The results of the shift-share of Kazakhstan are shown in Table 2. From the perspective of the regional share, the total growth of its three industrial sectors was lower than the share component for the entire area, but was higher after the first two periods, indicating that the economic shock at independence had a significant impact on the development of Kazakhstan's industries. When the economy resumed its growth, industries in Kazakhstan developed more quickly than those in the rest of Central Asia. From the perspective of the struc- 
tural deviation component, except for the negative values in the first period, those in the other two periods were all positive, indicating that the pulling effect of the industries on economic growth had gradually become prominent. Regarding the deviation component of competitiveness, the values of the primary and secondary sectors were positive only in the second period and negative in the other periods, indicating that Kazakhstan's agriculture and industry had become competitive only from 2000 to 2009 compared with the entire region. The value of the tertiary sector was positive in the first and second periods and negative after. This may reflect the relatively early development of the tertiary sector in Kazakhstan, and the slower growth and weaker competitiveness in recent years.

Table 2 Shift-share method analysis of Kazakhstan in different periods from 1990-2016

\begin{tabular}{clrrrrr}
\hline Period & Industry type & \multicolumn{1}{c}{$G j$} & \multicolumn{1}{c}{$N j$} & \multicolumn{1}{c}{$P j$} & \multicolumn{1}{c}{$D j$} & $(P D) j$ \\
\hline \multirow{3}{*}{$1990-1999$} & Primary & -46.18 & -4.38 & -29.26 & -12.54 & -41.80 \\
& Secondary & -134.86 & -45.52 & -77.32 & -12.02 & -89.34 \\
& Tertiary & -192.06 & -99.03 & -99.35 & 6.32 & -93.03 \\
& Primary & 28.90 & 3.02 & 21.53 & 4.35 & 25.88 \\
$2000-2009$ & Secondary & 295.32 & 108.03 & 164.42 & 22.87 & 187.29 \\
& Tertiary & 383.27 & 170.91 & 184.83 & 27.53 & 212.36 \\
& Primary & 16.15 & 2.38 & 24.17 & -10.41 & 13.77 \\
$2010-2016$ & Secondary & 62.48 & 58.13 & 85.33 & -80.98 & 4.36 \\
& Tertiary & 271.77 & 182.88 & 179.19 & -90.31 & 88.89 \\
\hline
\end{tabular}

Note: The table lists the total growth $G j$, regional share component $\mathrm{Nj}$, structural deviation component $P j$, competitiveness deviation component $D j$, and the total deviation component $(P D) j$. Tables 3-6 show the same.

The results of the shift-share analysis of Uzbekistan are shown in Table 3. The regional share component shows that the total growth of the primary sector was higher than the regional share component in the three periods, indicating that the development of the primary industry in Uzbekistan was higher than that at the regional level. The total growth of the secondary and tertiary sectors was lower than the regional share in the first period and higher in the latter two periods, indicating that the development of the secondary and tertiary sectors gradually exceeded the regional average. From the perspective of the structural deviation component, the values of the three sectors were all negative in the first period and became positive in 2000 , indicating that the status of the three sectors gradually rose. From

Table 3 Shift-share method analysis of Uzbekistan in different periods from 1990-2016

\begin{tabular}{clrrrrr}
\hline Period & Industry type & \multicolumn{1}{c}{$G j$} & $N j$ & \multicolumn{1}{c}{$P j$} & $D j$ & $(P D) j$ \\
\hline \multirow{3}{*}{$1990-1999$} & Primary & 1.77 & -1.68 & -11.18 & 14.63 & 3.45 \\
& Secondary & -24.31 & -11.55 & -19.61 & 6.86 & -12.76 \\
& Tertiary & -49.47 & -25.13 & -25.21 & 0.87 & -24.34 \\
& Primary & 27.64 & 2.53 & 18.02 & 7.10 & 25.12 \\
$2000-2009$ & Secondary & 44.27 & 28.11 & 42.78 & -26.62 & 16.16 \\
& Tertiary & 70.77 & 42.29 & 45.74 & -17.26 & 28.48 \\
& Primary & 33.06 & 2.53 & 25.69 & 4.84 & 30.53 \\
& Secondary & 41.17 & 11.56 & 16.98 & 12.63 & 29.61 \\
& Tertiary & 153.73 & 40.27 & 39.46 & 74.00 & 113.46 \\
\hline
\end{tabular}


the standpoint of the competitiveness deviation component, the primary sector was positive for the different periods, indicating strong competitiveness. The competitiveness deviation component for the secondary and tertiary sectors changed from positive to negative, and then again to positive in the third period, indicating that the secondary and tertiary industries had undergone a dynamic change in the competitiveness from strong to insufficient, and then had gradually strengthened and accelerated after 2010.

The results of the shift-share analysis of Tajikistan are shown in Table 4. The total growth of the three industrial sectors was lower than the regional share component in the first and higher in the latter two periods, which indicates that the development of the three industries had improved. For the structural deviation component, the values of the three sectors all changed from negative to positive, and those of the primary and tertiary industry continued to increase, indicating that their contribution to economic growth has continued to increase. For the competitiveness deviation component, the values of the primary and tertiary sectors were both negative in the first period and positive in the latter two periods. The value of the secondary sector did not become positive until the third period, indicating that it has been uncompetitive for a long time and only improved recently.

Table 4 Shift-share method analysis of Tajikistan in different periods from 1990-2016

\begin{tabular}{|c|c|c|c|c|c|c|}
\hline Period & Industry type & $G j$ & $N j$ & $P j$ & $D j$ & $(P D) j$ \\
\hline \multirow{3}{*}{ 1990-1999 } & Primary & -4.32 & -0.40 & -2.66 & -1.26 & -3.92 \\
\hline & Secondary & -15.83 & -3.17 & -5.39 & -7.26 & -12.66 \\
\hline & Tertiary & -17.97 & -5.38 & -5.40 & -7.18 & -12.59 \\
\hline \multirow{3}{*}{ 2000-2009 } & Primary & 5.55 & 0.31 & 2.21 & 3.03 & 5.24 \\
\hline & Secondary & 4.72 & 3.58 & 5.45 & -4.30 & 1.14 \\
\hline & Tertiary & 13.90 & 5.09 & 5.50 & 3.31 & 8.81 \\
\hline \multirow{3}{*}{ 2010-2016 } & Primary & 4.56 & 0.39 & 4.00 & 0.17 & 4.17 \\
\hline & Secondary & 4.19 & 1.36 & 2.00 & 0.83 & 2.83 \\
\hline & Tertiary & 13.21 & 6.08 & 5.96 & 1.17 & 7.13 \\
\hline
\end{tabular}

The results of the shift-share analysis of Kyrgyzstan are shown in Table 5. For the regional share component, the total increase in the primary sector was always higher than the regional share component, indicating a higher development over a long period. The total increase in the tertiary sector has been higher than that at the regional level since 2000, and that of the secondary sector has been higher since 2010, indicating that with the evolution of the industrial structure, the secondary and tertiary sectors have begun to gradually strengthen. For the structural deviation component, the value of each sector changed from negative for the first period to positive for the second period, indicating that each began to have a positive impact on economic growth after 2000, where the tertiary sector made a greater contribution. From the perspective of the competitiveness deviation component, the values of the primary and tertiary sectors were positive only in the first period. That of the secondary sector changed from negative to positive in the third period, indicating that primary and tertiary sectors were inadequately competitive, while the secondary industry was sufficiently competitive. 
Table 5 Shift-share method analysis of Kyrgyzstan in different periods from 1990-2016

\begin{tabular}{clrrrrr}
\hline Period & Industry type & $G j$ & $N j$ & \multicolumn{1}{c}{$P j$} & \multicolumn{1}{c}{$D j$} & $(P D) j$ \\
\hline \multirow{3}{*}{$1990-1999$} & Primary & 0.69 & -0.27 & -1.83 & 2.80 & 0.97 \\
& Secondary & -13.56 & -3.02 & -5.13 & -5.41 & -10.54 \\
& Tertiary & -7.49 & -3.95 & -3.96 & 0.43 & -3.53 \\
& Primary & 1.81 & 0.44 & 3.13 & -1.76 & 1.37 \\
$2000-2009$ & Secondary & 1.82 & 4.30 & 6.55 & -9.03 & -2.48 \\
& Tertiary & 10.13 & 7.12 & 7.70 & -4.70 & 3.00 \\
\hline \multirow{2}{*}{$2010-2016$} & Primary & 1.28 & 0.30 & 3.03 & -2.04 & 0.98 \\
& Secondary & 4.90 & 1.22 & 1.79 & 1.90 & 3.69 \\
\hline
\end{tabular}

The results of the shift-share analysis of Turkmenistan are shown in Table 6. With regard to the regional share component, the values of the primary sector in the first and second periods were lower than the regional value but increased significantly in the third period. The total increment in the secondary sector was always significantly higher than that of the regional share. The development for the tertiary sector began to surpass the overall level after 2000. For the structural deviation component, the values of the three sectors were all negative in the first period, indicating that they began to play a key role in economic growth starting in 2000. According to the magnitude of values of the components, the secondary and tertiary sectors formed a stronger driving force for economic growth than the primary sector. For the competitiveness deviation component, the value of the secondary sector was always positive and significantly higher than those of the other sectors, indicating the competitiveness of Turkmenistan's secondary industry. The competitiveness of the primary and tertiary sectors did not improve until 2010.

Table 6 Shift-share method analysis of Turkmenistan in different periods from 1990-2016

\begin{tabular}{clrrrrr}
\hline Period & Industry type & \multicolumn{1}{c}{$G j$} & \multicolumn{1}{c}{$N j$} & \multicolumn{1}{c}{$P j$} & $D j$ & $(P D) j$ \\
\hline \multirow{2}{*}{$1990-1999$} & Primary & -19.67 & -2.09 & -13.95 & -3.63 & -17.58 \\
& Secondary & 4.00 & -5.13 & -8.71 & 17.84 & 9.13 \\
& Tertiary & -21.87 & -10.70 & -10.74 & -0.43 & -11.17 \\
& Primary & 0.28 & 1.60 & 11.39 & -12.71 & -1.32 \\
$2000-2009$ & Secondary & 64.02 & 18.61 & 28.33 & 17.08 & 45.41 \\
& Tertiary & 31.71 & 19.50 & 21.09 & -8.88 & 12.21 \\
& Primary & 20.08 & 1.13 & 11.50 & 7.45 & 18.95 \\
\hline \multirow{2}{*}{$2010-2016$} & Secondary & 90.87 & 10.23 & 15.02 & 65.62 & 80.64 \\
& Tertiary & 56.60 & 19.32 & 18.93 & 18.35 & 37.28 \\
\hline
\end{tabular}

Figure 3 shows the results for the relative growth rate, structural effect index, and the regional competition effect index for the five Central Asian countries. We argue that when the relative growth rate of a country is higher than one, this reflects either the optimization of industrial structure and/or an improvement in competitiveness. Alternatively, if the relative growth rate is less than one, this suggests that one of the two economic indicators is lagging, thus restricting economic growth. 


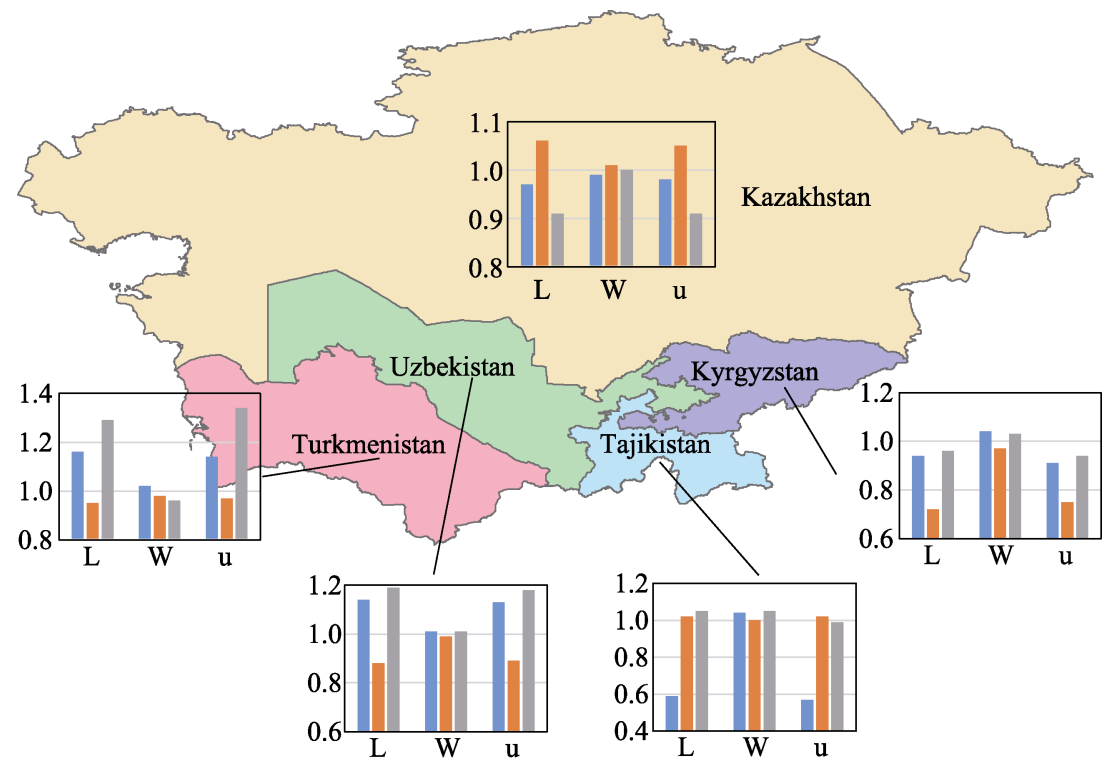

L: relative growth rate $\quad \mathrm{W}$ : structural effect index $\quad \mathrm{u}$ : regional competition effect index

-1990-1999 2000-2009 -2010-2016

Kazakhstan: country with structural advantage but low competitiveness

Uzbekistan: country with both strural and competitiveness advantages

Turkmenistan: country with competitiveness advantage

Tajikistan: country with stuctural advantage

Kyrgyzstan: country with low competitivenss

Figure 3 Comparative advantages of the evolutions of industrial structures in five Central Asian countries

The structural effect index of Kazakhstan has always been greater than one but its regional competition effect index was only greater than one in the second period, and decreased to 0.91 from 2010 to 2016, confirming a downward trend in industrial competitiveness. Moreover, the decline in competitiveness led to a relative growth rate of less than one, making Kazakhstan a country with structural advantages but lagging behind in terms of competitiveness. The relative growth rate of Uzbekistan has reached 1.19 in recent years. Both its structural effect index and the regional competition effect index have decreased and then increased. Combined with the above analysis, it is clear that these changes were caused mainly by changes in the competitiveness of its secondary and tertiary industries, and where the country was driven by both structural and competitive advantages. The regional competition effect index of Tajikistan was greater than one only in 2000-2009, and so the competitive advantage is not clear. The structural effect index, however, was greater than one in all periods, and the relative growth rate has been greater than one since 2000; thus, Tajikistan can be classed as a country driven by structural advantage.

The relative growth rate of Kyrgyzstan has been less than one for many years. Although its industrial structure is feasible, its regional competition effect index has been less than one for a long time, making Kyrgyzstan relatively uncompetitive and lagging behind the other four countries in the region.

The relative growth rate of Turkmenistan reached 1.29 during 2010-2016, with a higher economic growth rate than that of Central Asia. Although the structural effect index has been less than one in recent years, with a certain degree of irrationality to the industrial structure, 
the regional competition effect index has increased significantly. Thus, Turkmenistan is considered a competitively advantaged country.

\subsection{Analysis of industrial isomorphism in Central Asia}

The process of changes in the industrial structural in Central Asia not only presents the different characteristics of countries, but also features common to them. We can obtain the industrial isomorphism in Central Asian countries by measuring the average level of the similarity coefficient of industrial structure over the years 1990-2016 (Figure 4).

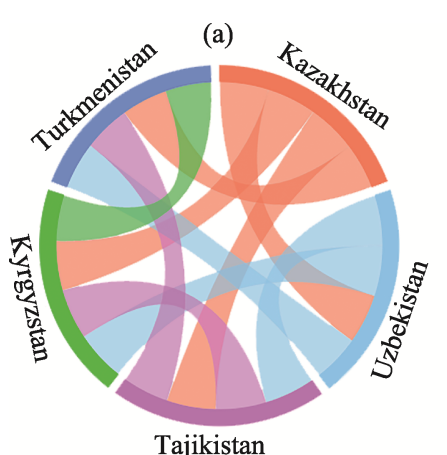

Tajikistan

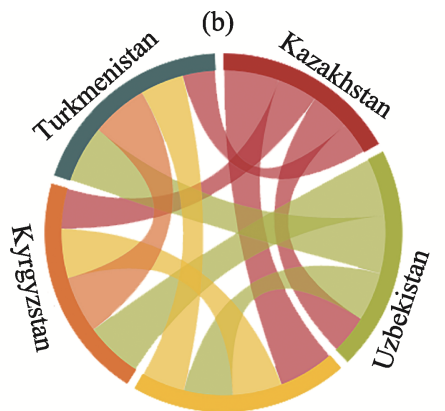

Tajikistan

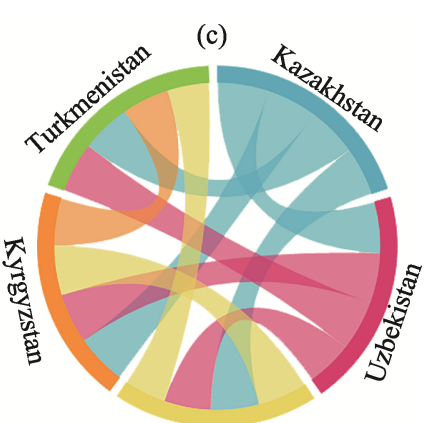

Tajikistan

Figure 4 Industrial isomorphism among the five Central Asian countries at different industrial levels

The structural similarity coefficients of the three industries for countries were over 0.9 , and those for Turkmenistan were above 0.95 . The coefficients for similarities between Uzbekistan and Kyrgyzstan, and Tajikistan and Kyrgyzstan were over 0.98, and that between Uzbekistan and Tajikistan was the highest, 0.9936. The coefficients for similarities between Kazakhstan and Uzbekistan, and Tajikistan, and Kyrgyzstan were 0.96-0.98, while those between Turkmenistan and the other four countries were relatively low, just over 0.85 . The problem of isomorphism at the three industrial levels among the five Central Asian countries is critical, mainly due to the limitation of resources and low economic development (Gao, 2013). As they had more diversified political and economic orientations after independence (Wang, 2004), the countries have failed to overhaul the unitary economic structure because they have not been independent for long. All of them rely on resources and raw materials as the driving force for economic growth. An important strategic direction of economic development for each country is to prioritize the oil and gas industry, which is lagging behind (Liu et al., 2016).

However, it is not sufficient to identify the industrial isomorphism at a broad level for the three industries in Central Asia. To gain a more comprehensive understanding of the similarity in industrial structure among them, similarities among the industrial subdivisions should also be calculated and analyzed. Based on the above analysis, it can be concluded that the foundation of the secondary industry is solid, and all countries except Turkmenistan have formed an industrial structure dominated by the tertiary industry. We thus calculate the structural similarity coefficients of the secondary and tertiary subindustries.

The similarity coefficient of the secondary industrial subdivisions highlights the problem of industrial isomorphism, but the degree of structural similarity has declined in relation to the three industrial levels. The structural similarity coefficient varied among countries. It exceeded 0.9 for the similarities between Kazakhstan and Kyrgyzstan, Uzbekistan and Kyr- 
gyzstan, Uzbekistan and Turkmenistan, and Kyrgyzstan and Turkmenistan, but was below 0.85 for the other countries, with the lowest value of 0.5592 for the similarity between Kazakhstan and Turkmenistan. The structural similarity coefficients of Kazakhstan and Uzbekistan, Kazakhstan and Kyrgyzstan, and Tajikistan and Turkmenistan were all in the range 0.6-0.8, while those of Uzbekistan and Tajikistan, and Uzbekistan and Kyrgyzstan were in the range $0.8-0.85$. The isomorphism of the internal secondary industry in Central Asia has thus decreased. On the contrary, affected by the "division of labor" policy of the Soviet Union, the developmental priorities of the countries were not alike. For instance, reliant on the metallurgical and chemical industries, Kazakhstan has mainly expanded heavy industry, while Tajikistan has focused on manufacturing, the non-ferrous metal industry, and the chemical industry. But in Uzbekistan, a relatively complete industrial system has been established, with particular stress on raw material production. Each country has developed some advantages in the secondary industry (Gang et al., 2015). For instance, the construction industry plays an important role in Kazakhstan's national economy while the power industry is the backbone of Kyrgyzstan's economy owing to its abundant hydropower resources. Uzbekistan, with a developed machine manufacturing industry, is capable of producing cotton planting, harvesting, and processing machinery, and is the only country in Central Asia that produces silk and spinning machinery. Furthermore, a pillar of Turkmenistan's economy is the natural gas sector and the building materials industry. In Tajikistan, aluminum production is the major economic driver, exemplified by the Tajik Aluminum Company. Because coal reserves are large in Central Asia, the coal mining and gas industries have grown (Gao, 2013; Gang et al., 2015; Xia et al., 2017).

The results show that although the similarity coefficients of the tertiary industrial subdivisions were lower than those for the three industries, they were significantly higher than that for the secondary industry. No isomorphism was evident in the tertiary industrial subdivisions of Tajikistan and Turkmenistan, and their similarity coefficient was only 0.8085 . But other countries exhibited isomorphism, with structural similarity coefficients between 0.89 and 0.99, of which the coefficients of Kazakhstan and Uzbekistan, and Kazakhstan and Kyrgyzstan were the highest, exceeding 0.98 . To promote economic growth, and broaden domestic production and consumption, Central Asian countries have attached increasing importance to the tertiary industry. The commerce and retail industry, telecommunication industry, and tourism industry are closely related to people's livelihood, require a large amount of labor, and thus form the main content of the tertiary industry in Central Asia. By focusing on the development of these industries, the countries have expanded domestic production and consumption, and boosted their economic growth. However, the diversification of the tertiary industry in Central Asia remains limited (Wang, 2004; Ding et al., 2017).

(a) Isomorphism among three industries; (b) Isomorphism among secondary industrial subdivisions; (c) Isomorphism among tertiary industrial subdivisions

\section{Discussion}

\subsection{Characteristics of evolution and interpretation of the industrial structure of the five Central Asian countries}

The history of economic development shows that the industrial structure of any region un- 
dergoes an evolution from unreasonable to reasonable, and from having a low to a high output (Wen, 2011). According to the results of this study, the evolution of the industrial structure in Central Asian countries has shown different trends. Due to differences in natural resources, the historical industrial structure, foundations for industrial development, strategy for economic development, and the degree of marketization, the characteristics of the evolution of the industrial structure in the five Central Asian countries are clearly different. The development of the three industrial sectors in Kazakhstan is ahead of the Central Asian region as a whole, and has tended to be rational. This situation is closely linked to positive economic development strategies and key national policies. The "import substitution" industrial plan (Ren and Yi, 2015) promoted the development of such industries as light industry, food industry, machine manufacturing, technology-intensive industries, transportation, and postal and telecommunications infrastructures. However, low competitiveness persists in various industries in the country. Low agricultural productivity, an energy-dependent economic structure, and the inability of the tertiary industry to absorb labor are the main causes of this problem (Sun et al., 2012). Uzbekistan has made significant progress in terms of industrial structure and competitiveness in recent years, mainly owing to gradual economic reforms that were implemented soon after independence. Emphasis was laid on ensuring national macroeconomic stability and ensuring the competitiveness of particular industries (Yang, 2012). Since the end of the civil war in 1997, the government has focused on developing the economy with the assistance of the international community. The economy has thus developed steadily and rapidly, which has rendered the structures of the three industrial sectors more rational. Our analysis showed that developments in the three major sectors were unbalanced, which is consistent with the fact that the country's agricultural development was relatively stable, the overall industrial development shrank, and the service industry developed rapidly (Huang, 2017). The positive impact of the evolution of the industrial structure in Kyrgyzstan on its economic growth became evident after 2000. However, many of its industries lagged behind those of other countries in competitiveness, with poor agricultural mechanization and governmental inefficiency. At the same time, from the perspective of industrial development, the country has not fully adapted to the transition from a planned economy to a market economy. The government has not implemented targeted industrial policies, and the service industry is only in its infancy (Muhammad, 2014). Turkmenistan's industry has a competitive advantage, especially its secondary industries, and its primary sector has become more competitive. This is consistent with a mature agricultural and industrial base, which includes the ongoing development of heavy industry, such as raw material extraction and primary processing. However, this also leads to an imbalance in the economic structure at the national level, whereby the heavy industry is relatively developed and the processing industry is backward (Zheng, 2009).

\subsection{Understanding the industrial isomorphism in Central Asia}

A certain degree of similarity was noted in the industrial structures of the Central Asian countries. The problem of industrial isomorphism occurred at different industrial levels. A few countries recorded relatively low similarity in the secondary subindustries. Considering the conditions in Central Asia, the high degree of industrial similarity is inevitable. First, the 
region is rich in energy and mineral resources, which determines the similarity of the countries' leading industries. Moreover, Central Asian countries are characterized by similar directions of industrial development as they are abundant in light and heat, grains, cotton, fruit, flowers, and livestock. This gives them a prominent advantage in agriculture. Second, influenced by the economic division of labor in the Soviet Union, mineral extraction and primary processing, and agriculture were the leading industries in Central Asian countries for a long time (Wei, 2015). Owing to their poor industrial structure and weak economic foundation, the similarities in their leading industries are unavoidable. For the sake of political stability, economic independence, and an improvement in domestic consumption, the authorities in most of these countries have adopted the strategy to advance economic growth by exporting domestic resources (Gao, 2013). While recognizing the industrial isomorphism, we should also realize its restrictive effect on regional economic development, especially on the process of economic integration in Central Asia. Due to the homogeneity and poor complementarity of the industrial structure, the demand for economic integration among these countries is limited (Liu et al., 2016). The Belt and Road Initiative has given impetus to advancing this integration, however. In this context, future research in the area should focus on ways to optimize the national economic structure of Central Asia and establish regional economic cooperation.

\subsection{Cooperation between China and Central Asian countries}

Easing the burden on its traditional industries is an important goal for China. The Chinese government needs to explore ways of motivating economic cooperation and foreign investment to cope with the slowdown in its economic growth. The Belt and Road Initiative has provided an opportunity for China and partner countries to develop the capacity for cooperation. As an important part of the Belt and Road region (Zhang, et al., 2018), Central Asia is important for economic cooperation, promoting the sustainable development of the domestic economy, expanding space for industrial development, and creating a new pattern of opening up. In capacity-related cooperation with Central Asian countries, capital-intensive industries among China's traditional industries, such as equipment manufacturing, can be transferred and realized through direct investment. Such a transfer combines China's advantages in these industries and in terms of capital with the infrastructure-related needs of Central Asian countries. Oil and gas extraction and processing, and the construction of a pipeline for transportation will also be major directions of investment. In agriculture, wheat, cotton, fruits, vegetables, and livestock products will be key areas for current and future cooperation. China and Central Asian countries should use the platform for international cooperation provided by the Belt and Road Initiative for mutual advantage.

\subsection{Limitations}

This paper introduced classic methods of industrial structural analysis and the relevant indicators to quantitatively examine the characteristics of the industrial structure and its spatio-temporal evolution in Central Asia from a diversity of perspectives. We first described the scale and structural characteristics of the industrial evolution of Central Asian countries. Based on the shift-share analysis method, a comparative analysis of the rationality and industrial competitiveness of these structures was conducted from three perspectives under the 
premise of placing the five Central Asian countries in the same reference system. Finally, the industrial isomorphic coefficient was introduced to examine the problem of industrial homogeneity among the countries. Using the quantitative results, we corroborated the history of the industrial development and its current situation in each country.

However, this study pays too much attention to the diversification of research perspectives and ignores the innovation in research methods. In future research, it is necessary to expand the research horizon and select more diverse methods to carry out industrial economic research. Data on the industries and subindustries of Central Asian countries used in this article were taken from the United Nations statistical database. This is the most complete data on industry in Central Asia according to subdivision. In future work, it is important to collect more detailed industrial data, such as those related to the scale of production. In addition, we can quantitatively research differences and complementarities in industry among the five Central Asian countries and China to provide support for the path of cooperation between them.

\section{Conclusions}

By taking Central Asia as research area, the evolutionary characteristics of the three regional industrial sectors and key subdivisions were examined in this study. The shift-share method was used to analyze the dynamic characteristics of the industrial sectors of each country from the standpoints of rationality and competitiveness. The contribution of the main industrial sectors to economic growth and their evolution were examined quantitatively by using the grey correlation method. The results showed the following: (1) The industrial structures in Central Asia have become more advanced and rational while their evolutionary characteristics are different. Kazakhstan has long displayed a tertiary-secondary-primary pattern of industrial activity, and productive services have played an increasingly prominent role in the development of the tertiary industry. The transformation of Uzbekistan's industrial structure has been apparent; the country had a secondary-tertiary-primary pattern upon independence and now has a tertiary-secondary-primary pattern. Tajikistan's industrial structure has changed significantly. In recent years, the secondary sector has been shrinking and the tertiary sector has developed rapidly. In Kyrgyzstan, the proportion of secondary and tertiary industries has been fluctuating significantly, but considerable progress has been made in the service sector. The industrial structure of Turkmenistan is significantly poorer than those of the other countries. It is the only country in the Central Asian region that still retains a secondary-tertiary-primary industrial pattern. (2) The rational and competitiveness of the industrial structures of the five countries displayed differing characteristics. Since 2000, the structural effect index of Kazakhstan has been greater than one but its regional competition effect index has dropped to 0.91 , reflective of a country with structural advantages but lagging in competitiveness. The structural effect index and the regional competitiveness effect index of Uzbekistan have increased to 1.01 and 1.18, respectively, in recent years. It is thus driven by both structural and competitive advantages. Tajikistan, with a structural effect index greater than one at each stage, is a typical country driven by structural advantage. The regional competition effect indices of Kyrgyzstan in the three stages of 1990-1999, 2000-2009, and 2010-2016 were $0.91,0.75$, and 0.94 respectively. It is a typical country with low competitiveness. Turkmenistan's regional competitiveness index was 1.34 , effec- 
tively driving up the relative growth rate and rendering it a typical country with competitive advantages. (3) The results of the degrees of industrial isomorphism in Central Asia show that the similarity coefficients of the three industrial structures between countries were higher than 0.95 , and those of the secondary subindustries in some countries were below 0.85 . The similarity coefficients of the tertiary subindustries for most countries were above 0.89 . That means that there was a considerable degree of similarity in the industrial structure among the Central Asian countries.

\section{References}

Bi Y R, Shi B, 2010. Measurement and analysis of trade potential between China and five Central Asian countries: Study of trade complementarity index and gravity model. Asia-Pacific Economic Review, (3): 47-51. (in Chinese)

Chang Q, 2001. Discussion on economic system and development model of five Central Asian countries. Social Sciences in Xinjiang, (1): 65-71. (in Chinese)

Ding Z G, Pan X Y, 2017. Evaluation and proposals of investment climate in Central Asian countries against the background of the Silk Road Economic Belt. Russian Central Asian \& East European Market, (2): 53-72. (in Chinese)

Duarte P., 2014. Central Asia: The planet's pivot area. Revista Española de Relaciones Internacionales, (6): 159-206.

Gang C C, Ren B P, 2015. The development mode of the five Central Asian countries on the background of the Silk Road Economic Belt. Reform, (1): 109-118. (in Chinese)

Gao Z G, 2013. An analysis of status quo and slow development of regional economic cooperation among Central Asian countries. Journal of Xinjiang University of Finance and Economics, (4): 12-18. (in Chinese)

$\mathrm{Hu} \mathrm{H} \mathrm{P}, 2004$. Analysis of economic situation of Central Asian countries. Russian Central Asian \& East European Market, (10): 20-26. (in Chinese)

Huang Q, 2017. Analysis of the problems of the three major industries in Tajikistan. Northern Economy and Trade, (2): 9-10. (in Chinese)

Kundsen D C, 2000. Shift-share analysis: Further examination of models for the description of economic change. Socio-Economic Planning Sciences, 34(3): 177-198.

Li L Q, Kong X, Li Y M et al., 2019. The selection of the strategic pivot in China-Central Asia cooperation under the Belt and Road Initiative. Geographical Research, 38(7): 1705-1719. (in Chinese)

Lu Q, Zhang C Y, 2008. An evidential analysis of the relation between the evolution of industrial structure and economic growth in Henan. China Population, Resources and Environment, 18(1): 111-115. (in Chinese)

Megoran N, Sharapova S, 2005. MacKinder's "heartland": A help or hindrance in understanding Central Asia's international relations? Central Asia and the Caucasus, 34(4): 8-20.

Ren Q L, Ivan S, 2015. A comparative study of industrial international competitiveness between Xinjiang, China and Kazakhstan. Finance \& Economics of Xinjiang, (2): 67-74. (in Chinese)

Shi T G, Zhang X L, Du H R et al., 2013. Manufacturing spatial distribution and structural characteristics in Central Asia. Arid Land Geography, 36(4): 749-756. (in Chinese)

Sun L, Fu L, Shen A B, 2012. Analysis of industrial structure evolution in Kazakhstan. Social Sciences in Xinjiang, (5): 76-81. (in Chinese)

Sun L, Wu H W, 2017. Annual Report on Development of Central Asia (2017). Beijing: Social Sciences Academic Press. (in Chinese)

Tang H, Chen D B, 2015. Development features and temporal-spatial evolution of economy in Central Asia in the past 20 years. Journal of University of Chinese Academy of Sciences, 32(2): 214-220. (in Chinese) 
Tang H, Yang D G, Chen D B et al., 2014. Development of energy industry and its impact on regional economy in the Central Asia. Arid Land Geography, 37(3): 630-637. (in Chinese)

The Belt and Road Initiative and the future of Central Asian economic integration. Modern Economic Information, (7): 154-155, 157. (in Chinese)

UNIDO, 1979. World Industry Since 1960: Progress and Prospects. New York: United Nations.

Wang H Y, 2002. Complementary analysis of economic cooperation between the five Central Asian countries and Xinjiang, China. East European, Russian \& Central Asian Market Studies, (2): 10-16. (in Chinese)

Wang H Y, 2004. Economic reforms and effects in five Central Asian countries. Russian Central Asian \& East European Market, (7): 12-18. (in Chinese)

Wang S J, Zhang M J, Chen F L et al., 2015. Comparison of GCM-simulated isotopic compositions of precipitation in arid Central Asia. Journal of Geographical Sciences, 25(7): 771-783.

Wang Y F, Hua Y T, 2008. The authentic research on the industry structure convergence in the Bohai Rim Region. Economy and Management, 22(2): 30-33. (in Chinese)

Wei M L, 2015. Study on industrial development and structural complementarity between Shaanxi province and five Central Asian countries. Journal of Shaanxi University of Technology (Social Sciences), 33(3): 64-70. (in Chinese)

Wen Y N, 2011. Comparison of industrial structure between Xinjiang, China and five Central Asian countries. Russian \& Central Asian Market Studies, (11): 25-33. (in Chinese)

Xian G Z, Tian C Y, 2017. Analysis of economic development in five Central Asian countries. China Business Update, (10): 31-36. (in Chinese)

Yang J H, 2012. Analysis of advantages and development status of characteristic industries in Uzbekistan. Economic Vision, (3): 68-70. (in Chinese)

Yang Y, Liu Y, Jin F J, 2015. Study on energy cooperation between China and the Central Asia and Russia under the view of energy geopolitics. Geographical Research, 34(2): 213-224. (in Chinese)

Zhang J Y, Chen Y I, Li Z, 2018. Assessment of efficiency and potentiality of agricultural resources in Central Asia. Journal of Geographical Sciences, 28(9): 1329-1340.

Zheng G F, 2009. Analysis on the system transition and economic development in Turkmenistan. Journal of Hexi University, (3): 67-72. (in Chinese)

Zhu X M, Xu S B, 2007. A review of Chinese regional convergence of industrial structure research. Human Geography, 22(2): 20-22, 86. (in Chinese) 